\title{
UNDERSTANDING THE HISTORY OF THE GREAT PATRIOTIC WAR AS THE MOST IMPORTANT ELEMENT OF HISTORICAL CONSCIOUSNESS FORMATION AND EDUCATION IMPROVEMENT
}

\author{
(Book Review: The Great Bend of the Don. The Place of Decisive Battles \\ of the Great Patriotic War in 1942-1943 [Text] / G. G. Matishov, V. I. Afanasenko, \\ E. F. Krinko, M. V. Medvedev. - Rostov-on-Don : Publishing house of SSC RAS, \\ 2016. -454 p.)
}

Nikolay F. Bugay

Institute of Russian History of RAS, Moscow, Russian Federation

Tatyana S. Bushueva

Institute of Russian History of RAS, Moscow, Russian Federation

\begin{abstract}
For the first time in the historiography, the problem of armed confrontation between the Red Army and the Wehrmacht is covered systematically and taking into account multiple factors, from the point of view of influence of geographic, political, demographic, social and economic conditions on the course of hostilities. The authors revive the memory of almost forgotten in the national historiography major tank battles of July 1942 on the southern wing of the Soviet-German front and prove that the number of armored vehicles and personnel strength is comparable with the most famous tank battle of Prokhorovka 1943. Assessing Order 227, the authors note that with this Order Stalin rejected the ideology of the "scythian war", expressed in ideas about the vastness of the territory, unlimitedness of grains, the possibility of luring the enemy deep into the vast country. The book describes in detail the part in the armed struggle Romanian, Italian, Hungarian and other troops on the Soviet-German front. In Eastern Europe their actions in modern historiography are considered to be heroic. The problem of lend-lease on the southern flank of the Soviet-German front via the "Persian corridor" is analyzed by the authors. The book analyzes such components of the General problems of military daily life as a front-line everyday life, organization of health services. Without a comprehensive analysis of all the circumstances, it is impossible to understand the general course of military operations, to explain the reasons of the defeats and victories of the Red Army.

Key words: large bend of the Don, Great Patriotic War, Stalingrad, losses, Wehrmacht, Eastern Front, occupation, evacuation of population.

Citation. Bugay N.F., Bushueva T.S. Understanding the History of the Great Patriotic War as the Most Important Element of Historical Consciousness Formation and Education Improvement (Book Review: The Great Bend of the Don. The Place of Decisive Battles of the Great Patriotic War in 1942-1943 [Text] / G. G. Matishov, V. I. Afanasenko, E. F. Krinko, M. V. Medvedev. - Rostov-on-Don : Publishing house of SSC RAS, 2016. - 454 p.). Vestnik Volgogradskogo gosudarstvennogo universiteta. Seriya 4, Istoriya. Regionovedenie. Mezhdunarodnye of otnosheniya [Science Journal of Volgograd State University. History. Area Studies. International Relations], 2018, vol. 23, no. 1, pp. 195-202. (in Russian). DOI: https://doi.org/10.15688/jvolsu4.2018.1.19
\end{abstract}




\title{
ОСМЫСЛЕНИЕ ИСТОРИИ ВЕЛИКОЙ ОТЕЧЕСТВЕННОЙ ВОЙНЫ КАК ВАЖНЕЙШЕЕ НАПРАВЛЕНИЕ ФОРМИРОВАНИЯ ИСТОРИЧЕСКОГО СОЗНАНИЯ И СОВЕРШЕНСТВОВАНИЯ ОБРАЗОВАНИЯ
}

\author{
(Рец. на кн.: Большая излучина Дона. Место решающих сражений \\ Великой Отечественной войны 1942-1943 гг. [Текст] / Г. Г. Матишов, \\ В. И. Афанасенко, Е. Ф. Кринко, М. В. Медведев. - Ростов н/Д : \\ Изд-во ЮНЦ РАН, 2016. - 454 с.)
}

\author{
Николай Федорович Бугай \\ Институт российской истории РАН, г. Москва, Российская Федерация \\ Татьяна Семеновна Бушуева \\ Институт российской истории РАН, г. Москва, Российская Федерация
}

\begin{abstract}
Аннотация. Впервые в историографии системно, многофакторно раскрыта проблема вооруженного противоборства Красной Армии и вермахта с точки зрения воздействия на ход боевых действий географических, политических, демографических, социальных и экономических условий. Актуализирована важность природного фактора как активно воздействовавшего на исход военных действий. Игнорирование этого фактора привело к тому, что потери, понесенные личным составом в результате болезней, обморожений, физического и морального истощения, оказались вполне сопоставимы с боевыми потерями от огневых средств. Авторы возрождают память о практически забытых в отечественной историографии крупных танковых сражениях июля 1942 г. на южном крыле советско-германского фронта и доказывают, что по количеству бронетехники и численности личного состава соединений они вполне сопоставимы с самым известным танковым сражением под Прохоровкой 1943 года. Авторы, оценивая приказ № 227, отмечают, что Сталин самим содержанием приказа отверг идеологию «скифской войны», выражавшуюся в представлениях о необъятности территории, неистощимости запасов, о возможности заманивания врага вглубь огромной страны. В книге подробно описано участие в вооруженной борьбе на советско-германском фронте румынских, итальянских, венгерских и других войск. Их действия в современной историографии Восточной Европы героизируются. Достаточной новизной отличается рассмотренная авторами проблема поставок по ленд-лизу на южном фланге советско-германского фронта через «персидский коридор». В книге проанализированы такие составляющие общей проблемы военной повседневности, как фронтовые будни, организация санитарной службы. Патриотическая позиция авторов книги нашла отражение в подробном исследовании ими мемориальной памяти о боевых действиях в большой излучине Дона. В книге отмечается, что сражения в большой излучине Дона сыграли существенную роль в истории Великой Отечественной войны. Без комплексного анализа всех обстоятельств происходивших здесь боев нельзя понять общий ход военных действий, объяснить причины поражений и побед Красной Армии.

Николай Федорович Бугай дал оценку общественно-политическим процессам, освещенным в монографии, историографии, политике памяти, осуществил общее редактирование текста рецензии. Татьяна Семеновна Бушуева дала характеристику всему, что касается военных трактовок темы.

Ключевые слова: большая излучина Дона, Великая Отечественная война, Сталинград, потери, вермахт, Восточный фронт, оккупация, эвакуация населения.
\end{abstract}

Цитирование. Бугай Н. Ф., Бушуева Т. С. Осмысление истории Великой Отечественной войны как важнейшее направление формирования исторического сознания и совершенствования образования (Рец. на кн.: Большая излучина Дона. Место решающих сражений Великой Отечественной войны 1942-1943 гг. [Текст] / Г. Г. Матишов, В. И. Афанасенко, Е. Ф. Кринко, М. В. Медведев. - Ростов н/Д : Изд-во ЮНЦ РАН, 2016. - 454 с.) // Вестник Волгоградского государственного университета. Серия 4, История. Регионоведение. Международные отношения. - 2018. - Т. 23, № 1. - C. 195-202. - DOI: https://doi.org/10.15688/jvolsu4.2018.1.19 
В современных условиях, очевидно, что историческая наука выступает не только как важнейший фактор познания прошлого, она активно используется в политических процессах, способствуя формированию в социуме патриотической гражданской позиции, сохранению национальной идентичности, формированию самосознания и национального сознания.

История научного знания о Великой Отечественной войне 1941-1945 гг. прошла долгий и сложный, наполненный событиями путь. Нарастающий инновационный прорыв в исследовании этой фундаментальной темы отечественной историографии стал очевиден уже на излете XX столетия, когда появились возможности критического осмысления достигнутого, отказ от наслоений прежнего уровня бездоказательности в изучении темы.

Возникавшие события, имевшие переломное значение, и главный гуманитарный прорыв в деле открытия засекреченных архивов обусловили объективный процесс переосмысления привычных оценок и даже концепций (параллельно в историографии сложилось целое направление, приверженцы которого резко возражают против переосмысления истории, называя это вульгарным ее «переписыванием»). Однако очевидным стало и другое: нравственные категории в современном обществе, как на пространстве СНГ, так и в ряде зарубежных стран, все чаще подменяются информационными войнами памяти для активизации негативного чувства по отношению к России.

Заметным событием в историографии истории Великой Отечественной войны 19411945 гг,, безусловно, стало представленное широкой читательской аудитории исследование профессионалов военной темы Г.Г. Матишова, В.И. Афанасенко, Е.Ф. Кринко и М.В. Медведева: «Большая излучина Дона место решающих сражений Великой Отечественной войны 1942-1943 гг.». Проблема, рассмотренная авторским коллективом, все еще относится к малоизвестным страницам истории Великой Отечественной войны, преимущественно из-за сохранявшегося десятилетиями воздействия политической и идеологической конъюнктуры. Именно по этой причине при знакомстве с работой возникает вопрос: возможно ли было ее издание несколько десяти- летий тому назад. Реальным ли было такое актуальное, острое, с неприемлемыми ранее выводами, с обнародованием ранее абсолютно невозможных для публикации документальных свидетельств, но вместе с тем скрупулезное, фундированное большим объемом источников рассмотрение событий тяжелейшего периода войны 1942-1943 годов. Ответ однозначный: конечно, нет.

Тема книги не единожды становилась уже предметом исследования историков предшествовавших поколений: и сразу по горячим следам войны, и в советской историографии, и в период так называемого «застоя», и, конечно, «перестройки». Описание событий, происходивших в большой излучине Дона, иными словами, ожесточенного противостояния советских и германских (с сателлитами) войск, присутствует (конечно, с разной степенью полноты и понимания значимости событий) во множестве работ, и, конечно же, в многотомных изданиях по истории войны, выпущенных в разные периоды.

Но нельзя не отметить то, что преимущественно в советской историографии острота происходивших в рассматриваемый период событий не могла быть воспроизведена с полнотой оценок происходившего во многом из-за нежелания представителей военного и политического руководства того времени, на котором вольно или невольно, но лежало бремя тяжелых потерь личного состава Красной Армии. И только в сложившихся условиях доступности ранее совершенно секретной источниковой базы, в том числе трофейных материалов крупнейших хранилищ - ЦАМО РФ, ГА РФ, РГАСПИ, региональных архивов, в условиях открытости и плюрализма научных дискурсов стал возможен объективный подход к исследуемой проблематике вооруженного противоборства мощнейших вооруженных группировок Красной Армии и вермахта, любой ценой рвавшегося в Сталинград.

Структура книги охватывает все основные проблемы, связанные с рассматриваемыми событиями, причем важно, что ход вооруженной борьбы раскрывается системно, многофакторно, без игнорирования оценок действий противника, к тому же представлены сопутствующие главной теме проблемы: географические, политические, демографичес- 
кие, социальные, экономические. И это справедливо, так как рассматривать вооруженную борьбу изолированно от других проблем или только с точки зрения канонов советского военного искусства было бы неправомерно.

Однако уже в первой главе книги заметно концептуальное авторское новшество, которое, можно предположить априори, может вызвать у ряда читателей недоумение. Дело в том, что при описании вооруженного противоборства сторон в ходе коренного перелома в войне авторы предлагают прежде всего рассмотреть «Природный фактор в сражениях в большой излучине Дона». Это отличает данное исследование от общепринятого концептуального подхода к описанию боевых действий, который всегда основывался на таких составляющих, как-то: планы и замыслы сторон, обстановка, соотношение сил и т. д. Все это, конечно, присутствует у авторов при дальнейшем изложении текста, но практически впервые столь значимо актуализируется среди прочих именно природный фактор как активно воздействовавший на ход и исход войны.

Авторы следующим образом обосновывают свою точку зрения: «Пока еще недостаточно раскрыта и роль природного фактора в событиях коренного перелома в Великой Отечественной войне на юге страны, несмотря на появление ряда публикаций в последние годы» (из четырех указанных авторами сносок на вышедшие работы три принадлежат им самим). И далее авторский вывод по первому разделу главы следующий: «Таким образом, географические условия в значительной степени определяли развитие событий в большой излучине Дона в период Великой Отечественной войны. Свое влияние оказывали особенности рельефа, включая изгибы русла Дона и его притоков, сам характер прилегающей местности, сложившаяся транспортная инфраструктура, особенно наличие переправ через реки как естественные барьеры на пути продвижения войск. Все эти факторы сказывались на ходе и результатах боевых действий в 1942-1943 гг.» (с. 30).

Надо отметить, что материал в главе чрезвычайно интересен именно с точки зрения анализа географической составляющей, насыщен новыми параметрами. В итоге среди группы факторов, оказывавших кардиналь- ное влияние на ход вооруженных действий в 1942-1943 гг., авторами оценены как преимущественные: особенности рельефа, конфигурации русла, длина Дона, изменчивость гидрологического режима рек и подземных вод, температуры влажности воздуха, осадков и другие абиотические и биотические процессы» (с. 14). Касаясь «природного фактора», авторы напомнили читателю пушкинскую мудрую стихотворную строку из истории 1812 г.: «...кто тут нам помог? Остервенение народа, Барклай, зима иль русский Бог?» Но, как видно, Пушкин факторы победы 1812 г. расставил в несколько иной, чем авторы, последовательности.

Представляется, что солдатам тех сражений такие термины, как «абиотические и биотические процессы» вряд ли были известны или понятны. Им просто пришлось в ходе жесточайших боев еще превозмочь почти 50-градусную жару, нехватку воды и, напротив, крепкие морозы. Это все подробно описано в рецензируемой книге.

Малоизвестный и острый материал скомпонован авторами во 2-м параграфе 1-й главы и озаглавлен вновь с учетом воздействия на воевавших природного фактора: «строительство оборонительных рубежей и весенний паводок 1942 г.». Речь идет о важности задачи, стоявшей перед советским руководством по созданию столь необходимой в складывавшихся условиях эшелонированной обороны. И далее авторы показывают на уникальных свидетельствах, как же эта задача решалась. Лишь некоторые фрагменты из книги:

- «...с утра до ночи копали траншеи и противотанковый ров. Очень трудно копать, земля каменистая, так что постоянно натыкались на камни, которые приходилось разбивать киркой... Кормили очень плохо. Давали соус морковный...» (с. 33);

- «10 тысяч рабочих, колхозников, служащих, студентов Калмыкии, пройдя 250 км до пункта назначения... выполнили огромный объем земляных работ - вырыли и перебросили свыше 1,5 млн куб. м грунта» (с. 34);

- «снова надо было строить оборонительные сооружения, ...земля не копалась, спина не разгибалась, желудок сводило от голода» (с. 35).

И уже совсем жесткий факт - постановление ГКО от 27 декабря 1941 г. о неожидан- 
ном сокращении строительства оборонительных рубежей. К тому же работы по возведению оборонительных сооружений, например, бюро Ростовского обкома партии признало «совершенно неудовлетворительными». Самоотверженный, к тому же ручной труд строителей по возведению оборонительных сооружений, во многом пропал из-за паводка, где под современными песками залегали до 1012 м лиманно-аллювиальные отложения. Но, как свидетельствуют материалы, не только паводок оказался виновен: «Проверка выявила плохое состояние рубежей обороны, существенно пострадавших не только от плохих условий, но и из-за расхищения строительных материалов... Возводимые рубежи подвергались систематическим разорениям как со стороны самих строителей, так и местного населения» (с. 39).

Авторами приведены многочисленные факты того, как героические усилия людей сводились на нет правившей системой: «Весной после таяния снега и разлива рек, многие уже построенные укрепления в пойме Дона оказались затоплены и пришли в негодность... Возведенные укрепления не позволили сдержать врага, ...построенные рубежи на Дону и под Сталинградом... не смогли стать непреодолимым препятствием для противника» (с. 48).

Авторы акцентируют внимание читателей на серьезном влиянии метеоусловий на ход боевых действий, из-за которых приходилось нести потери и оказывалось невозможным использовать в боях ни танки, ни авиацию, а артиллерия нередко била не по целям, а в туман.

Весьма ценен авторский вывод и для современных вооруженных сил Российской Федерации о необходимости учета природного фактора и условий в ходе ведения боевых действий. Игнорирование этих факторов в рассматриваемый конкретный временной период Великой Отечественной войны привело к тому, что «потери, понесенные личным составом в результате болезней, обморожений, физического и морального истощения (как следствие того, что командование недостаточно учитывало природный фактор), вполне сопоставимы с боевыми потерями от огневых средств» (с. 68).

При дальнейшем изложении событий авторы придерживаются общепринятой отрабо- танной в историографии при описании военных действий схемы. Насыщена новыми материалами глава 2-я под названием «Накануне тяжелых испытаний». Помещенные в ней карты и схемы существенно дополняют текстовую часть. Авторский вывод по главе объективен, однако, несколько расходится с общепринятым в историографии: «К началу летнего наступления 1942 г. немецкое командование обеспечило благоприятную для себя оперативную обстановку на южном крыле Восточного фронта, усилило войска модернизированными танками, самоходными штурмовыми орудиями, противотанковыми орудиями, способными эффективно поражать советские танки Т-34 и КВ. Ставка ВГК и командование советских фронтов на южном крыле советско-германского фронта не сумело определить замыслы, силы противника, и организовать прочную эшелонированную оборону, несмотря на превосходство в численности личного состава, в количестве танков.

В июле 1942 г. создававшееся положение привело к катастрофическим последствиям - прорыву врага в большую излучину Дона, к Волге, в предгорья Кавказа, захвату огромной территории на юге СССР» (c. 94). Авторы воспроизводят на основе новых архивных источников трагические страницы катастрофы советских войск в Крыму, под Харьковом в мае 1942 года. Это позволило немецкому командованию перехватить стратегическую инициативу на южном крыле советско-германского фронта, создать благоприятные условия для летнего наступления вермахта на Кавказ и к Волге в ее нижнем течении (с. 104).

Авторы возрождают память о практически забытых в отечественной историографии военного искусства, но происходивших в период Великой Отечественной войны крупных танковых сражениях:

«В июле 1942 г. на южном крыле советскогерманского фронта произошли три крупных танковых сражения, по количеству бронетехники и численности личного состава соединений вполне сопоставимых с самым известным танковым сражением Великой Отечественной войны, состоявшимися под Прохоровкой 12-13 июля 1943 г., ...но в отличие от событий Прохоровки 1943 г., танковые сражения в большой излучине Дона в июле 1942 г. исследованы недостаточно. 
В советской историографии не обнаружено анализа причин огромных потерь танковых войск РККА в этих сражениях» (с. 105).

Можно добавить из личных свидетельств, как в советское время в закрытом режиме военные историки, исследовавшие Сталинградскую битву, Федор Данилович Воробьев и Василий Павлович Морозов на доступных им тогда секретных материалах обсуждали эти вопросы в Институте военной истории Министерства обороны.

«Первой Прохоровкой» 1942 г. авторы называют танковое сражение в районе Горшечное, подчеркивая, что «суммарные потери в танках войск Брянского фронта в первой Прохоровке июля сорок второго года составили 719 единиц» (ссылка на 500-й фонд трофейных документов в ЦАМО). Авторы приводят материалы и об огромных потерях советских войск в окружении под Миллерово, где «...погибли тысячи наших солдат, десятки тысяч оказались в плену» (с. 113). Новой источниковой базой наполнены авторские тексты об обороне Ростова-на-Дону и Новочеркасска в июле 1942 г., когда «суммарные потери действовавшей здесь 56-й армии за 2125 июля 1942 г. составили свыше 100000 человек...».

Немецкие части на рубежах РОР и в уличных боях в Ростове потеряли около 10 тыс. солдат и офицеров, в том числе 2402 убитыми и пропавшими без вести (c. 156). По оперативным данным 56-й армии, враг потерял убитыми около 10900 человек. И хотя советским войскам в большой излучине Дона удалось избежать катастрофических окружений, но в ходе боевых действий потери в личном составе и вооружении здесь были огромными - 568347 бойцов и командиров (среднесуточные за 27 дней 21050 человек).

Авторы не скрывают документы о резком падении морального духа у советских войск, деморализации части бойцов и командиров, вызванных непрерывными успехами вермахта (с. 158), факты бегства значительной части местных партийных и советских руководителей с собственными семьями и оставившими население врагу.

В книге анализируется такой источник, как материалы органов военной цензуры, в которых зафиксированы конкретные сведения, а также оценки и высказывания о предательстве командного и политического состава, в результате чего возникла растерянность и потеря управления. Такие сведения вряд ли могли быть пропущены цензурой советского времени для обнародования. Однако они чрезвычайно важны для воссоздания подлинной, а не идеологизированной истории войны.

Не обошли авторы и один из знаковых документов истории войны - приказ № 227: «Сталин самим содержанием приказа, по сути, отверг идеологию “скифской войны”, накрепко въевшуюся в сознание командиров и бойцов и выражавшуюся в представлениях о необъятности территории, неистощимости запасов, о заманивании врага вглубь огромной страны» и далее достаточно резкое суждение, но во многом близкое к объективному: «между тем в июле 1942 г. неорганизованное отступление советских войск сопровождалось разрушением четкой структуры армий и фронтов, их превращением в неуправляемую вооруженную толпу...» (с. 164). И вывод: «Только ценой неимоверных усилий частям Красной Армии удалось остановить войска вермахта в предгорьях Кавказа и на Волге» (с. 169).

Авторы подробно на основе источников рассматривают основные военные события, развернувшиеся на подступах к Сталинграду. Чрезвычайно насыщен материалами и рассуждениями авторов раздел 2-й главы 4-й «Экзамен на профпригодность, или Почему советские маршалы в мемуарах замалчивали операции РККА в большой излучине Дона в 1942-1943 гг.». Авторский вывод на базе скрупулезного анализа биографий, послужных списков сводится к констатации невысокого уровня командного состава РККА. Имеется в виду с точки зрения преимущественно его оперативно-стратегического уровня, то есть командующих армиями и фронтами (с. 207).

Новыми источниками отличаются материалы главы «Разгром нацистского интернационала в большой излучине Дона», где подробно описано участие в вооруженной борьбе на советско-германском фронте румынских, итальянских, венгерских и других войск, появление которых на советской территории существенно осложнило ситуацию для Красной Армии. Историография отечественная и стран 
восточной Европы эту проблему затрагивала множество раз, однако в работах последнего времени, как справедливо заметили авторы, «в историографии бывших социалистических стран проявляется тенденция к переоценке данной проблемы. Если ранее господствовали представления о том, что венгерские, румынские, словацкие, хорватские солдаты воевали и гибли вдали от родины за чуждые им цели, что превращало их из соучастников чуть ли не в жертв фашистской агрессии, то теперь имеет место новое явление - происходит на практике их реабилитация и даже героизация» (с. 9-10). На Восточном фронте, по последним данным, приведенным в рецензируемой книге, летом 1942 г. было 710 тыс. румын. На Кавказ вела наступление словацкая дивизия, участвовавшая в штурме Ростова-на-Дону. В большой излучине Дона действовали добровольцы из Скандинавских стран и Голландии. Итальянцы потеряли 84830 тыс. убитыми, ранеными, пропавшими без вести и плененными.

Достаточной новизной отличается постановка авторами и тематики, и приводимого конкретного материала, в том числе статистического, связанного с так называемыми «каспийскими конвоями». «Речь идет о роли поставок по ленд-лизу через “персидский коридор" в успехах Красной Армии на южном фланге советско-германского фронта» (с. 244). По утверждению авторов, «в период напряженных оборонительных сражений в большой излучине Дона и под Сталинградом объемы поставок по "персидскому коридору" лендлиза в мае - июне и сентябре - октябре 1942 г. составили от 87 до 121 тыс. т, что доходило почти до 53 \% от общего объема поставок по всем маршрутам ленд-лиза» (с. 254).

В постсоветской историографии востребованной стала тема о военной повседневности. Не обошли ее и авторы рецензируемой работы, проанализировав такие составляющие, как фронтовые будни, организация санитарной службы. Значительный пласт источников составил основу главы «Власть и население», в которой рассмотрены проблемы эвакуации населения, особенности нацистской оккупации, казачий вопрос на Дону в годы войны, зафиксированные как в официальных документах, так и альтернативно - в свидетельствах очевидцев.
Патриотическая позиция авторов книги нашла отражение в подробном исследовании ими в главе 8-й мемориальной памяти о боевых действиях в большой излучине Дона. На базе новых источников приведена мемориальная статистика людских потерь и материального ущерба вследствие боевых действий, эвакуации и оккупации. Занимая активную гражданскую позицию, авторы обращают внимание на то, что не всегда память о подвиге предшествующих поколений сохраняется должным образом. Они пишут: «Обращает внимание то, что отдельные памятники находятся в неудовлетворительном состоянии. Так, 19 апреля 2009 г. упали трехметровые фигуры героев-комсомольцев... в самом центре Волгограда. Другие мемориалы подвергаются действиям вандалов».

Авторы итожат свое исследование выводом: «Сражения в большой излучине Дона сыграли существенную роль в истории Великой Отечественной войны. Без комплексного анализа всех обстоятельств, происходивших здесь боев, нельзя понять общий ход военных действий, объяснить причины поражений и побед Красной Армии» (с. 395).

Как уже принято в исторических исследованиях, альфой и омегой труда являются две его важных составляющих: обзор историографии и источниковедческий анализ. Так, если историография проблемы присутствует в достаточно полном аналитическом изложении, в том числе зарубежная и наиболее полно немецкая, то обзора источников в книге нет, авторы ограничились лишь библиографическим перечнем использованных фондов и материалов.

В основном представленная книга может рассматриваться в качестве значимой составляющей современной историографии истории Великой Отечественной и в целом Второй мировой войны, ее необходимо рекомендовать научному активу и экспертам организации «Бессмертный полк России» при подсчете потерь ушедших поколений соотечественников; она может рассматриваться как важное подспорье в освоении данной темы работниками образования и высшей школы. Она важна и для участников ток-шоу СМИ с точки зрения донесения объективной информации о происходивших важных событиях периода войны в противовес малозна- 
чимым и недостоверным оценкам, путающим и раздражающим людей.

Материалы исследования могут быть актуализированы также в ходе международных конференций, в частности при рассмотрении вопросов участия сателлитов Германии в войне, что, очевидно, заинтересует ученых таких стран, как Италия, Румыния, Хорватия, Словакия, Венгрия и др.

В целом книга - ценная основа для дальнейшей популяризации и актуализации патриотического знания о Великой Отечественной войне в формате исторической политики современной России.

\section{Information about the Authors}

Nikolay F. Bugay, Doctor of Sciences (History), Professor, Chief Researcher, Institute of Russian History of RAS, Dm. Ulyanova St., 19, 117292 Moscow, Russian Federation, nikolay401@yandex.ru, https://orcid.org/0000-0002-8363-1638

Tatyana S. Bushueva, Candidate of Sciences (History), Leading Researcher, Institute of Russian History of RAS, Dm. Ulyanova St., 19, 117292 Moscow, Russian Federation, t_bush@mail.ru, https:// orcid.org/0000-0002-7298-768X

\section{Информация об авторах}

Николай Федорович Бугай, доктор исторических наук, профессор, главный научный сотрудник, Институт российской истории РАН, ул. Дм. Ульянова, 19, 117292 г. Москва, Российская Федерация, nikolay401@yandex.ru, https://orcid.org/0000-0002-8363-1638

Татьяна Семеновна Бушуева, кандидат исторических наук, ведущий научный сотрудник, Институт российской истории РАН, ул. Дм. Ульянова, 19, 117292 г. Москва, Российская Федерация, t_bush@mail.ru, https://orcid.org/0000-0002-7298-768X 